\title{
Genetic diversity and relationships among populations of Camellia japonica, an endangered species in China
}

\author{
Kai Yang, Yingkun Sun, Wei Li, Xiao Guo, Qinghua Liu, and Handong Gao
}

\begin{abstract}
Camellia japonica, an evergreen ornamental plant in the Theaceae family, has a natural range that is now shrinking. This is evident by the fact that the species is on the verge of extinction in Laoshan Mountain (Qingdao), the northernmost area of China known to have a natural population of $C$. japonica. Little is known about the genetic diversity and relationships among cultivated and wild $C$. japonica populations. One hundred and eighty samples of six $C$. japonica populations were tested for genetic diversity with simple sequence repeat (SSR) markers; these included three cultivated populations, two natural populations in Qingdao, and one natural population in Daqingshan. The average values of polymorphism information content (PIC), expected heterozygosity (He), and Shannon's information index (I) were $0.5849,0.6385$ and 1.3170 , respectively, indicating that $C$. japonica has a high genetic diversity. The genetic diversities of the six populations in rank order were as follows: Daqingshan $>$ Zhongshan Park $>$ Changmenyan Island $>$ Daguan Island $>$ Botanical Garden $>$ May Fourth Square. The geographical isolation of the islands had no significant influence on the genetic diversity of $C$. japonica. Clustering results showed that the six $C$. japonica populations could be grouped into three categories, and most populations were clustered according to their geographical origin and genetic background. These results also reconfirmed that the $C$. japonica (Naidong) population in Qingdao originated from Changmenyan Island. Genetic variation was highest within populations (89\%), indicating that $C$. japonica can be protected at the population level. These findings will prove useful for the genetic analysis, protection, and horticultural use of $C$. japonica.
\end{abstract}

Key words: SSR markers, natural population, Camellia japonica, cultivated population, genetic structure.

Résumé : L'aire de répartition naturelle de Camellia japonica, conifère ornemental de la famille des Theaceae, rétrécit. La preuve? L'espèce a pratiquement disparu sur le mont Laoshan (Qingdao), territoire le plus au nord de la population naturelle, en Chine. On sait peu de choses sur la diversité génétique et les liens entre les populations sauvages et domestiques de $C$. japonica. Dans l'espoir d'y remédier, les auteurs ont examiné la diversité génétique de 180 échantillons de six peuplements du conifère avec des marqueurs SSR, en l'occurrence trois populations domestiques, deux naturelles dans le Qingdao et une naturelle dans le Daqingshan. La valeur moyenne du contenu polymorphe (PIC), le degré d'hétérozygotie prévu (He) et l'indice de Shannon (I) s'établissaient respectivement à 0,5849 , à 0,6385 et à 1,3170 , signe que $C$. japonica profite d'une très grande diversité génétique. Sur ce plan, les six populations peuvent se classer comme suit : Daqingshan $>$ parc Zhongshan $>$ île Changmenyan $>$ île Daguan > jardin botanique > parc du Quatre-Mai. L'isolement géographique des îles n'a eu aucune influence déterminante sur la diversité génétique de l'espèce. L'analyse des résultats par grappes indique que les six populations de C. japonica pourraient être groupées en trois catégories et que la majorité des peuplements sont regroupés d'après leur origine géographique et leurs antécédents génétiques. Ces données confirment à nouveau que la population de C. japonica (Naidong) du Qingdao vient de l'île Changmenyan. Le plus important degré de variation génétique s'observe au sein de chaque peuplement (89\%), ce qui signifie qu'on pourrait protéger l'espèce à ce niveau. Ces constatations auront leur utilité pour l'analyse du génome, la protection de l'espèce et l'usage de cette dernière en horticulture. [Traduit par la Rédaction]

Mots-clés : marqueurs SSR, population naturelle, Camellia japonica, population domestique, structure génétique.

Received 7 February 2021. Accepted 8 May 2021.

K. Yang. College of Biology and the Environment, Nanjing Forestry University, Nanjing 210037, People's Republic of China; College of Landscape Architecture and Forestry, Qingdao Agricultural University, Qingdao 266109, People's Republic of China.

Y. Sun, W. Li, X. Guo, and Q. Liu. College of Landscape Architecture and Forestry, Qingdao Agricultural University, Qingdao 266109, People's Republic of China.

H. Gao. College of Biology and the Environment, Nanjing Forestry University, Nanjing 210037, People’s Republic of China.

Corresponding authors: Qinghua Liu (email: 200001033@qau.edu.cn) and Handong Gao (email: gaohd@njfu.edu.cn).

(C) 2021 The Author(s). This work is licensed under a Creative Commons Attribution 4.0 International License (CC BY 4.0), which permits unrestricted use, distribution, and reproduction in any medium, provided the original author(s) and source are credited. 


\section{Introduction}

Camellia japonica belongs to the Theaceae family. As one of the top ten traditional famous flowers of China, it has high economic and ornamental value. It is a subcanopy tree (Yamamoto 1992) and its wild populations are widely distributed in Sichuan, Taiwan, Jiangxi, and Shandong provinces and on many islands along the eastern coast of China (Zhang and Ren 1998; Gao et al. 2005). Zhejiang province is the center for natural populations of $C$. japonica in southern China. The species is also found on the Korean Peninsula and on the southern islands of Japan (Kang and Huh 2014; King 2018). C. japonica is found mainly on hillsides facing the sea or in the forest understory of coastal islands. The Daqingshan scenic area of the Zhoushan Islands in Zhejiang is a representative area that contains some natural $C$. japonica populations. Laoshan Mountain in Qingdao and the adjacent island, due to their favorable mild oceanic climate, are the northernmost areas where $C$. japonica plants can be found. The wild $C$. japonica population in this area and the cultivated population derived from it are commonly known as $C$. japonica (Naidong). As a relict plant population, C. japonica (Naidong) was common in the Tertiary geologic period and is regarded as the original gene pool of northern C. japonica (Zhou et al. 1994; Wang et al. 1995). Therefore $C$. japonica (Naidong) has significant ecological value.

C. japonica (Naidong) was once a dominant species of the islands, naturally distributed on offshore islands in a longitude range of $120^{\circ} 37^{\prime}-121^{\circ} 13^{\prime}$ and a latitude range of $36^{\circ} 07^{\prime}-36^{\circ} 18^{\prime}$ (Wang et al. 2001). However, because of limited resources and habitat changes caused by human activities (e.g., building, harvesting, and excavation), the natural population is shrinking, and $C$. japonica (Naidong) has become an endangered plant (Wang and Zhang 1992). As the world population has grown and human activities have adversely affected the environment, the conservation of biodiversity has attracted widespread attention. Plant conservation includes the preservation of genetic diversity within and among populations and the maintenance of population numbers (Stinchcombe and Hoekstra 2008). Genetic diversity represents a particularly important component of conservation (Charles et al. 2018) because it affects species' adaptability, ecosystem stability, and sustainability (Hughes et al. 2008; Szczeciníska et al. 2016). To effectively protect $C$. japonica, its genetic diversity should first be characterized (Brian 2009).

The genetic diversity of natural $C$. japonica population has been examined by a few research, mainly using allozymes, amplified fragment length polymorphisms (AFLPs), and inter simple sequence repeats (ISSRs) (Oh et al. 1996; Chung and Chung 2000; Zhang 2008; Lin et al. $2012 a, 2012 b)$. All of these approaches are dominant marker systems and therefore have a limitated ability to precisely evaluate the diversity of $C$. japonica, an outcrossing species. Simple sequence repeats (SSRs) have the advantages of co-dominance, good polymorphism, and stable amplification conditions (Xie et al. 2010), and they are capable of distinguishing homozygous and heterozygous genotypes. Therefore, genetic diversity estimates may be higher when SSR markers are used (Li et al. 2020). SSR and expressed sequence tag (EST)SSR markers based on transcriptome sequencing have recently been used to analyze the genetic relationships among C. japonica germplasms (Zhang et al. 2016; Zhao et al. 2017; Pan et al. 2019), but SSRs have not been used to analyze the genetic relationships among $C$. japonica populations. In addition, most AFLP and ISSR studies of C. japonica have focused on natural populations on islands. Genetic diversity and the relationships between cultivated and natural populations have not been studied to date.

Humans have spontaneously cultivated wild C. japonica to protect it and ensure its reproduction, and these efforts have increased its population density. Natural populations of $C$. japonica (Naidong) are primarily found on Changmenyan Island and Daguan Island in Qingdao, whereas cultivated populations are found in three parks, the Botanical Garden, Zhongshan Park, and May Fourth Square in Qingdao (Wang 2006). In this study, we used SSR molecular markers to analyze the genetic diversity and relationships among five C. japonica (Naidong) populations in Qingdao in northern China and one $C$. japonica population in Daqingshan in southern China. The influences of geographic isolation and human factors on the genetic structure of the different populations were clarified. These results provide a scientific basis for the protection and utilization of C. japonica germplasm resources.

\section{Materials and Methods}

\section{Sample collection}

One hundred and eighty individuals of $C$. japonica were collected from six populations in northern and southern China (Fig. 1): May Fourth Square (Pop I) (Qingdao, Shandong, China), Botanical Garden (Pop II) (Qingdao), Zhongshan Park (Pop III) (Qingdao), Daguan Island (Pop IV) (Qingdao), Changmenyan Island (Pop V) (Qingdao), and Daqingshan (Pop VI) (Zhoushan, Zhejiang, China). Populations I-V are from the northern region where populations of $C$. japonica (Naidong) are concentrated, and Pop VI is a representative population from the southern range of its distribution. Populations I-III are cultivated populations, and Pop IV-VI are natural populations. From September to December 2017, an interval sampling method (Joshi et al. 2000) was used to collect samples from 30 individuals in each population: 2-4 young leaves were collected from the top of the stem of each individual, and sampled plants were located at least $50 \mathrm{~m}$ from a conspecific plant. The leaves were placed immediately into self-sealing plastic bags with dry color-indicating silica gel and transported back to the 
Fig.1. Locations of the $C$. japonica populations sampled in this study. The left map shows the region in China from which six C. japonica populations were sampled (Map world, 2021), the middle map shows the locations of three natural C. japonica populations sampled in Qingdao, Shandong Province and Zhujiajian, Zhejiang Province (Map world, 2021), and the right map shows the locations of the three cultivated C. japonica populations sampled in Qingdao (Arcgis topographic map, 2021). [Colour online.]
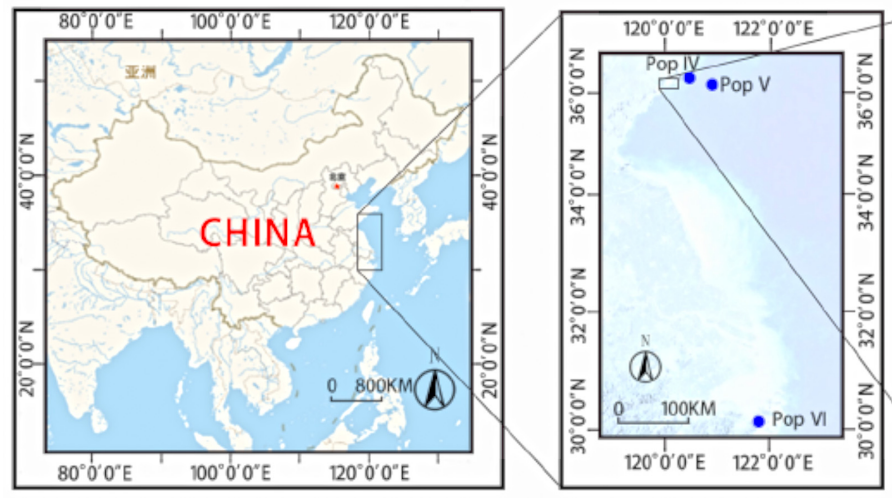

laboratory within 2-3 h. After washing and drying, the samples were stored in $\mathrm{a}-80{ }^{\circ} \mathrm{C}$ freezer for future use.

\section{DNA extraction}

Genomic DNA was extracted from the samples using a modified cetyl trimethyl ammonium bromide (CTAB) method (Li et al. 2009). The concentration and purity of the DNA were measured using $2 \%$ agarose gel electrophoresis and UV spectroscopy, and the samples were dissolved in $1 \times \mathrm{TE}$ buffer and stored at $-20{ }^{\circ} \mathrm{C}$ for future use.

\section{PCR amplification and primer selection}

The $20 \mu \mathrm{L}$ SSR polymerase chain reaction (PCR) reaction system contained $7.2 \mu \mathrm{L} \mathrm{dd}_{2} \mathrm{O}, 10 \mu \mathrm{L} \mathrm{Mix}, 0.3$ $\mu \mathrm{L}$ forward primer, $0.3 \mu \mathrm{L}$ reverse primer, $2 \mu \mathrm{L}$ DNA template, and $0.2 \mu \mathrm{L}$ Taq enzyme. The amplification procedure was as follows: pre-denaturation at $94{ }^{\circ} \mathrm{C}$ for $5 \mathrm{~min}$; 35 cycles of denaturation at $94{ }^{\circ} \mathrm{C}$ for $30 \mathrm{~min}$, annealing at $54{ }^{\circ} \mathrm{C}$ for $35 \mathrm{~s}$, and extension at $72{ }^{\circ} \mathrm{C}$ for $40 \mathrm{~s}$; and final extension at $72{ }^{\circ} \mathrm{C}$ for $3 \mathrm{~min}$. All PCR products were verified by capillary electrophoresis on an ABI 3730xl instrument (Applied Biosystems, Waltham, MA, USA). The electrophoresis results were photographed and analyzed using GeneMarker V2.2.0 software.

Four samples of DNA templates were randomly selected from $180 \mathrm{C}$. japonica individuals, and 64 pairs of primers were selected for primer screening based on previous SSR studies of $C$. japonica and related plants (Fang et al. 2012; Chen et al. 2016; Zhang et al. 2016). The PCR products were added to the upper sample buffer, denatured at $94{ }^{\circ} \mathrm{C}$ for $10 \mathrm{~min}$, and then analyzed by vertical electrophoresis on a $6 \%$ denatured polyacrylamide gel. Twenty pairs of primer sequences were selected based on the results of this preliminary

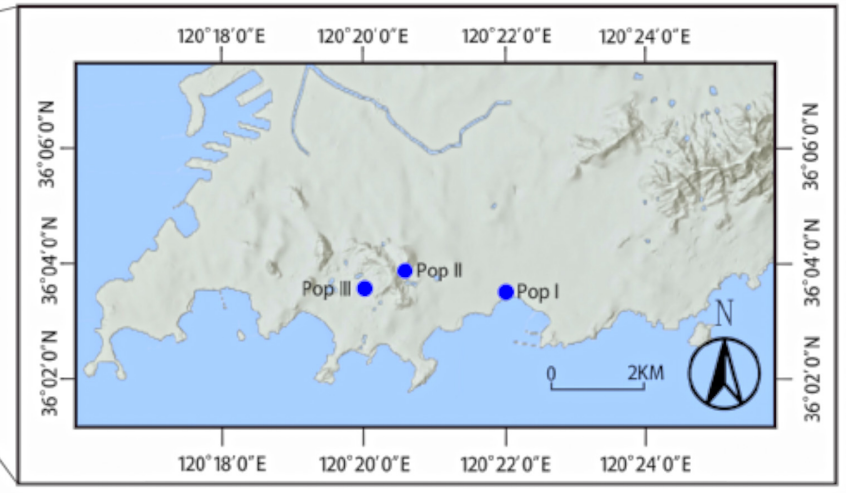

experiment (Table 1 and Supplementary Fig. S1 ${ }^{1}$ ). Primer synthesis was performed at Huada Gene Company.

\section{Statistical analysis}

Capillary electrophoresis was performed using the ABI $3730 x 1$ gene sequencer, and the resulting raw data were analyzed with Fragment (plant) analysis software in GeneMarker. The position of each sample peak was compared with the molecular weight size markers in each lane to determine the fragment size. POPGENE version 1.32 software (Yeh et al. 1997) was used to calculate the effective number of alleles per loci (Ne), the expected heterozygosity (He), and the observed heterozygosity (Ho). The polymorphic information content (PIC) values of all loci were calculated using the online program PICcalc (Nagy et al. 2012). GenAlEx version 6.5 (Peakall and Smouse 2012) was used to estimate F-statistics, including the self-crossing rate within the population $\left(F_{i s}\right)$, the self-crossing rate among the populations $\left(F_{i t}\right)$, the population differentiation rate $\left(\mathrm{F}_{\mathrm{st}}\right)$, the gene flow among different populations $\left(\mathrm{N}_{\mathrm{m}}\right)$, and the principal coordinate analysis (PCoA). Analysis of molecular variance (AMOVA) in Arlequin 3.0 software (Excoffier et al. 2005) was used to estimate the genetic variation among and within populations and to conduct the significance test of genetic differentiation of the populations. The genetic distance was used to determine the genetic differences between various populations using the method described by Nei (1972). Based on the genetic distance, an unweighted pair group with arithmetic mean (UPGMA) dendrogram (Felsenstein 1984) constructed with NTSYS 2.1 (Rohlf 1988) was used to perform cluster analysis on various populations to construct a phylogenetic tree. The delta $\mathrm{K}$ criterion was analyzed with the

${ }^{1}$ Supplementary data are available with the article at https://doi.org/10.1139/CJPS-2021-0034. 
Table 1. Twenty pairs of SSR primers.

\begin{tabular}{|c|c|c|c|c|}
\hline $\begin{array}{l}\text { Primer } \\
\text { number }\end{array}$ & Forward primer sequence & Reverse primer sequence & $\begin{array}{l}\text { Amplicon } \\
\text { length (bp) }\end{array}$ & $\begin{array}{l}\text { Fluorescent } \\
\text { marker }\end{array}$ \\
\hline P1 & TATTGCCTACGACCATTTCCA & TTTGAGTTCGTTGCCTTCTCT & 190-230 & 5'FAM \\
\hline P2 & AAGAAGAGCAGAGCAACAAGTG & ССАСАСАСТTТССАСАСТTTТG & $180-230$ & 5'HEX \\
\hline P3 & TGССССТААТTTTCTАТСТTT & GGGAAATTGCTTACTCTCATT & $160-200$ & 5'TMRA \\
\hline P17 & GTGGGTTACGGGTTTA & TTTGAGTTCGTTGCCTTCTCT & $210-260$ & 5'FAM \\
\hline P18 & GCGTATGGAAAAGCTGAGAA & ССАСАСАСТТТССАСАСТТTТG & $140-180$ & $5^{\prime} \mathrm{FAM}$ \\
\hline P19 & TATTGCCTACGACCATTTCCA & GGGAAATTGCTTACTCTCATT & $180-230$ & 5'FAM \\
\hline P21 & ССАTCATTGGCCATTACTACAА & CCATATGTGTGTGAATGATAAAACC & 140-180 & 5'TMRA \\
\hline P22 & GGTGTGGTGTTTTGAAGAAA & TGTTAAGCCGCTTCAATGC & $160-200$ & 5'HEX \\
\hline P23 & GTGAAGTTAGTTGTTACTCTTTTTTGG & AGGGGAAGTGAGGAGGCAT & $200-230$ & 5'FAM \\
\hline P27 & GGCTTGGACACTTGGTTAGA & AAGATGGATTAGGGTAGGAT & $160-200$ & 5'TMRA \\
\hline P28 & TGGCCGATCGGGATTCAAT & TGACCAAACAGCTCATGCG & $160-200$ & 5'HEX \\
\hline P37 & АCGCTTCTGTTTGGTCTATT & GATCTTGCTCATCCСTTCAC & 150-180 & $5^{\prime} \mathrm{HEX}$ \\
\hline P39 & ATAGGTCTTTGTCTGGTT & AAGATGGATTAGGGTAGGAT & $210-250$ & $5^{\prime} \mathrm{FAM}$ \\
\hline P40 & AATAAGAATCGGTGACCTCTG & СТTСАТТААССССТАААСТААААС & $130-160$ & $5^{\prime} \mathrm{HEX}$ \\
\hline P43 & ССАAАACCCTAGTTTCACTCCA & ATCAAACGCTCTGTATCGGTG & $240-289$ & 5'FAM \\
\hline P49 & TTTTGGTTGCCTCGCCTCC & TGCTTCCСTCTAGGTCCСTCC & $160-180$ & 5'TMRA \\
\hline P53 & GCTAATGATAGACCATCTGCTCCT & GGCCATGCTCTCAATAGTAGAACT & $140-170$ & 5'FAM \\
\hline P54 & TTACATCTCTTTTGCAGCTGTCGG & СTTCGGGAACTTCTGCTTCATC & $150-180$ & 5'FAM \\
\hline P55 & ССТСТССTTGССTTTСАTTTC & GCCACGGTTTTCTTCTCCTC & 140-170 & $5^{\prime} \mathrm{FAM}$ \\
\hline P58 & AGGGGACGGATCTCATATCGT & GACTTCCTCACCGGAGTGCTT & $190-230$ & $5^{\prime} \mathrm{HEX}$ \\
\hline
\end{tabular}

program STRUCTURE HARVESTER (Earl and vonHoldt 2012). The genetic structure diagram of the six $C$. japonica populations was created using STRUCTURE 2.0 (Evanno et al. 2005). SRUCTURE analysis was performed with 200,000 replicates burn-in length and 1200,000 iterations of iterations Markov chain Monte Carlo (MCMC) from $\mathrm{K}=2$ to $\mathrm{K}=10$. Independent STRUCTURE runs were 6 conducted for each specialized $\mathrm{K}$.

\section{Results}

\section{Genetic diversity of $C$. japonica populations}

Polymorphic alleles were amplified using 20 pairs of SSR primers (Table 2). The PIC values of these loci ranged from 0.3188 to 0.8177 , with an average of 0.5849 , revealing a high level of genetic diversity among $C$. japonica plants in China. Loci with low polymorphism (PIC $<0.25)$, moderate polymorphism $(0.25<\mathrm{PIC}<0.5)$, and high polymorphism (PIC $>0.5$ ) accounted for $0 \%$, $25 \%$, and $75 \%$ of all loci, respectively, indicating that the SSR primers used in this study were highly reliable (Ashburner et al. 2000). The number of observed alleles (Na) at each locus ranged from 3 to 22; the average number of alleles was 9, and the total number of alleles was 180 . The effective number of alleles per locus $(\mathrm{Ne})$ ranged from 1.7620 to 6.1393 , with a mean of 3.1842 . The Shannon information index (I) ranged from 0.6253 to 1.9900 , with a mean of 1.3170 . Nei's gene diversity (GD) values indicated that there was a large amount of genetic diversity at all loci and ranged from 0.3817 to 0.8371 . Observed heterozygosity (Ho) ranged from 0.2444 to 0.9722 , and expected heterozygosity $(\mathrm{He})$ ranged from
0.3827 to 0.8394 . The average He $(0.6385)$ was larger than the average $\mathrm{Ho}(0.5024)$, indicating low heterozygosity of C. japonica.

The genetic diversity among $C$. japonica populations based on SSR analysis is shown in Table 3. The mean values of $\mathrm{Na}$ and $\mathrm{Ne}$ were 4.8250 and 2.9538, respectively, and the Na and Ne of Pop VI were clearly higher than those of the other five populations. Values of I and GD at the population level were 1.1414 and 0.5978 , respectively, and I and GD were also highest in Pop VI. The average value of He was 0.6086 , and that of Pop VI was highest, but Ho of Pop VI showed the opposite pattern. The percentages of polymorphic loci (PPL) in the six C. japonica populations were all $100 \%$. Among the C. japonica (Naidong) populations, $\mathrm{Na}, \mathrm{Ne}, \mathrm{I}, \mathrm{He}$, and GD were higher in Pop III than in the other four populations, although Ho had an intermediate value in Pop III. Pop IV and Pop V had similar genetic diversity values, as did Pop I and Pop II. Thus, the genetic diversities of the six populations in rank order were: Daqingshan (Pop VI) $>$ Zhongshan Park (Pop III) $>$ Changmenyan Island (Pop V) $>$ Daguan Island (Pop IV) $>$ Botanical Garden (Pop II) $>$ May Fourth Square (Pop I). Ho was lower than He in all six $C$. japonica populations. These results were consistent with the geographic locations of the six populations (Fig. 1), indicating that environmental conditions may influence the genetic diversity of C. japonica.

\section{Genetic structure of $\boldsymbol{C}$. japonica populations}

We analyzed the genetic differentiation index and gene flow of $C$. japonica populations based on the SSR 
Table 2. Diversity statistics of 20 SSR loci across $C$. japonica populations.

\begin{tabular}{llllllll}
\hline Locus & PIC & $\mathrm{Na}$ & $\mathrm{Ne}$ & $\mathrm{I}$ & Ho & He & $\mathrm{GD}$ \\
\hline P1 & 0.5249 & 10 & 2.3453 & 1.1851 & 0.4000 & 0.5752 & 0.5736 \\
P2 & 0.7642 & 12 & 4.8474 & 1.7560 & 0.6056 & 0.7959 & 0.7937 \\
P3 & 0.5096 & 6 & 2.4442 & 1.0460 & 0.9722 & 0.5925 & 0.5909 \\
P17 & 0.7522 & 17 & 4.4588 & 1.9202 & 0.6000 & 0.7779 & 0.7757 \\
P18 & 0.4576 & 6 & 2.1134 & 0.9452 & 0.4556 & 0.5283 & 0.5268 \\
P19 & 0.5149 & 10 & 2.2877 & 1.1750 & 0.3611 & 0.5645 & 0.5629 \\
P21 & 0.7815 & 22 & 4.9522 & 2.1663 & 0.4556 & 0.8003 & 0.7981 \\
P22 & 0.6597 & 7 & 3.4703 & 1.3812 & 0.3820 & 0.7138 & 0.7118 \\
P23 & 0.3504 & 4 & 1.7858 & 0.6704 & 0.2556 & 0.4412 & 0.4400 \\
P27 & 0.5663 & 3 & 2.7682 & 1.0583 & 0.6556 & 0.6405 & 0.6387 \\
P28 & 0.3188 & 4 & 1.6172 & 0.6253 & 0.4000 & 0.3827 & 0.3817 \\
P37 & 0.4382 & 6 & 2.0456 & 0.9042 & 0.4056 & 0.5126 & 0.5111 \\
P39 & 0.5891 & 3 & 2.9687 & 1.0934 & 0.7167 & 0.6650 & 0.6631 \\
P40 & 0.7684 & 12 & 4.7894 & 1.8838 & 0.2889 & 0.7934 & 0.7912 \\
P43 & 0.7212 & 11 & 4.0505 & 1.7151 & 0.6222 & 0.7552 & 0.7531 \\
P49 & 0.6767 & 13 & 3.5602 & 1.5611 & 0.5111 & 0.7211 & 0.7191 \\
P53 & 0.3413 & 3 & 1.7620 & 0.6381 & 0.2444 & 0.4337 & 0.4325 \\
P54 & 0.6020 & 7 & 2.9297 & 1.2834 & 0.6111 & 0.6605 & 0.6587 \\
P55 & 0.8177 & 11 & 6.1393 & 1.9900 & 0.6333 & 0.8394 & 0.8371 \\
P58 & 0.5437 & 13 & 2.3477 & 1.3423 & 0.4722 & 0.5757 & 0.5741 \\
Mean & 0.3188 & 9 & 3.1842 & 1.3170 & 0.5024 & 0.6385 & 0.6367 \\
St. Dev & 0.4382 & 5.0576 & 1.2920 & 0.4685 & 0.1772 & 0.1361 & 0.1357 \\
\hline
\end{tabular}

Note: Abbreviations: Na, number of observed alleles; Ne, number of effective alleles; I, Shannon information index; Ho, observed heterozygosity; He, expected heterozygosity; GD, Nei's gene diversity.

Table 3. Genetic diversity of $C$. japonica populations.

\begin{tabular}{llllllll}
\hline Populations & $\mathrm{Na}$ & $\mathrm{Ne}$ & $\mathrm{I}$ & $\mathrm{Ho}$ & $\mathrm{He}$ & GD & PPL (\%) \\
\hline Pop I & 4.1000 & 2.5195 & 0.9906 & 0.4583 & 0.5442 & 0.5351 & 100.00 \\
Pop II & 4.1000 & 2.5447 & 1.0016 & 0.4667 & 0.5641 & 0.5547 & 100.00 \\
Pop & 5.5500 & 2.9983 & 1.2458 & 0.5067 & 0.6431 & 0.6324 & 100.00 \\
Pop & 4.2000 & 2.7906 & 1.0642 & 0.5152 & 0.5925 & 0.5826 & 100.00 \\
Pop & 4.8000 & 2.7594 & 1.0947 & 0.5537 & 0.5918 & 0.5846 & 100.00 \\
Pop & 6.2000 & 4.1100 & 1.4516 & 0.4895 & 0.7160 & 0.6972 & 100.00 \\
Mean & 4.8250 & 2.9538 & 1.1414 & 0.4984 & 0.6086 & 0.5978 & 100.00 \\
\hline
\end{tabular}

Note: Abbreviations: Na, number of observed alleles; Ne, number of effective alleles; I, Shannon information index; Ho, observed heterozygosity; He, expected heterozygosity; GD, Nei's gene diversity; PPL, percentage of polymorphic loci.

markers (Table 4). F-statistics $\left(\mathrm{F}_{\text {is }}, \mathrm{F}_{\mathrm{it}}\right.$, and $\left.\mathrm{F}_{\text {st }}\right)$ and gene flow $\left(\mathrm{N}_{\mathrm{m}}\right)$ analysis of the six populations showed that only four loci had negative F-statistics. The remaining sixteen loci had positive values, indicating that the proportion of populations with heterozygotes was low and the degree of purity of the populations was high, consistent with the values of He and Ho in $C$. japonica individuals and populations (Table 2 and Table 3 ). The average $F_{i s}, F_{i t}$, and $F_{s t}$ were $0.1651,0.2332,0.0816$, respectively (Table 4). The genetic differentiation of the different populations was analyzed based on the $\mathrm{F}_{\mathrm{st}}$ and $\mathrm{N}_{\mathrm{m}}$ values. The average $\mathrm{F}_{\mathrm{st}}$ across all loci was 0.0816 , indicating that there was clear genetic differentiation among the $C$. japonica populations. The average $\mathrm{N}_{\mathrm{m}}$ was 2.8148 , confirming that there was a moderate to high degree of genetic differentiation among the populations.

The AMOVA results showed that the highest genetic variation occurred within $C$. japonica populations (89\%); the genetic variation among populations was only $11 \%$ (Table 5). Genetic variation among $C$. japonica populations was therefore low, and genetic variation arose mainly within members of individual C. japonica populations.

\section{Relationships among $C$. japonica populations}

The genetic similarity coefficients of the six $C$. japonica populations ranged from 0.6738 to 0.9874 (Table 6). The genetic similarity coefficient was highest between the May Fourth Square (I) and the Botanical Garden populations in Qingdao (II), and lowest between the five 
Table 4. F-statistics and gene flow at 20 SSR loci of six C. japonica populations.

\begin{tabular}{lcrlr}
\hline Locus & \multicolumn{1}{l}{$\mathrm{F}_{\text {is }}$} & \multicolumn{1}{l}{$\mathrm{F}_{\text {it }}$} & \multicolumn{1}{l}{$\mathrm{F}_{\text {st }}$} & $\mathrm{N}_{\mathrm{m}}$ \\
\hline P1 & 0.1820 & 0.3092 & 0.1555 & 1.3575 \\
P2 & 0.1951 & 0.2498 & 0.0680 & 3.4265 \\
P3 & -0.6545 & -0.6185 & 0.0217 & 11.2630 \\
P17 & 0.1911 & 0.2561 & 0.0804 & 2.8606 \\
P18 & 0.0751 & 0.1195 & 0.0480 & 4.9591 \\
P19 & 0.2718 & 0.3918 & 0.1647 & 1.2676 \\
P21 & 0.3612 & 0.4395 & 0.1225 & 1.7911 \\
P22 & 0.4721 & 0.4970 & 0.0473 & 5.0392 \\
P23 & 0.4329 & 0.4642 & 0.0552 & 4.2764 \\
P27 & -0.0456 & -0.0101 & 0.0340 & 7.1097 \\
P28 & -0.0598 & -0.0183 & 0.0392 & 6.1353 \\
P37 & 0.0846 & 0.2422 & 0.1722 & 1.2020 \\
P39 & -0.1205 & -0.0663 & 0.0484 & 4.9150 \\
P40 & 0.6064 & 0.6409 & 0.0875 & 2.6071 \\
P43 & 0.1499 & 0.2044 & 0.0640 & 3.6543 \\
P49 & 0.1889 & 0.3040 & 0.1419 & 1.5118 \\
P53 & 0.4650 & 0.4897 & 0.0462 & 5.1666 \\
P54 & 0.0542 & 0.0949 & 0.0430 & 5.5603 \\
P55 & 0.2234 & 0.2669 & 0.0561 & 4.2096 \\
P58 & 0.0996 & 0.2176 & 0.1310 & 1.6586 \\
Mean & 0.1651 & 0.2332 & 0.0816 & 2.8148 \\
\hline
\end{tabular}

Note: Abbreviations: $F_{\text {is }}$, self-crossing rate within the population; $F_{i t}$, self-crossing rate between the populations; $\mathrm{F}_{\mathrm{st}}$, population differentiation rate; $\mathrm{N}_{\mathrm{m}}$, gene flow estimated as $\mathrm{N}_{\mathrm{m}}=\left[\left(1 / \mathrm{F}_{\mathrm{st}}\right)-1\right] / 4$.

C. japonica (Naidong) populations (I-V) and the southern C. japonica population (VI).

The unweighted pair group method with arithmetic mean (UPGMA) dendrogram of $C$. japonica was reconstructed based on genetic distance values (Fig. 2). UPGMA clustering of the six populations indicated that the genetic distance was $\mathbf{0 . 1 8 1 8}$, and the populations could be grouped into three classes. Class I contained Pop I, Pop II, Pop III, and Pop V; class II contained Pop IV; and class III contained the southern $C$. japonica population, Pop VI.

Cluster analysis was performed based on differences in the allele frequencies of different individuals. The relationship between $\Delta \mathrm{K}$ and $\mathrm{K}$ was determined using the method described by Evanno (2005) (Figs. $3 a$ and 3b). The largest $\Delta K$ occurred at $K=3$, and this value of $K$ was therefore used to obtain a reasonable clustering division of the populations. The 180 individuals in the six populations could be divided into three genetically distinct groups (Fig. 3c). Most samples from Pop I, Pop II, Pop III and Pop V fell into one group, whereas Pop IV and Pop VI were placed in separate groups.

To further evaluate the genetic variation of different C. japonica populations, a principal coordinate analysis (PCoA) was performed. This PCoA indicated that the six populations divided into three clusters (Fig. 4): in one were Pop I, Pop II, Pop III and PopV, the other two groups consisted of Pop IV and Pop VI, respectively. The PCoA results were consistent with the clustering from the UPGMA (Fig. 2).

\section{Discussion}

\section{Genetic diversity of $C$. japonica}

Genetic diversity analysis of a species can provide guidance for its genetics and breeding, and the study of genetic structure and differentiation assists with the protection and utilization of germplasm resources (Wolf and Harrison 2001). Hamrick (1989) analyzed 449 plants in 165 genera and reported that the average genetic diversity index (He) was 0.11 within plant populations and 0.15 at the species level. Fang et al. (2012) used SSR markers to analyze the genetic diversity of $C$. sinensis cultivars and reported He values of 0.543. Expressed sequence tag-simple sequence repeat (EST-SSR) markers were developed for $C$. reticulata, a native plant of southwestern China, and analysis showed that the $\mathrm{He}$ values of $C$. reticulata, $C$. saluenensis, $C$. pitardii, and C. yunnanensis were 0.457, 0.342, 0.235, and 0.168, respectively (Tong and Gao 2020). Using EST-SSR markers, the average He of $C$. japonica cultivars was 0.638 (Pan et al. 2019), consistent with the He values reported here for 180 C. japonica samples (0.6385). Our findings also indicate that the genetic diversity of $C$. japonica is much higher than that of other Camellia species and woody plants. The Shannon information index (I) is also an important indicator that reflects population genetic diversity. Compared with the I value reported here (1.1414), the I values of Camellia populations from other species calculated from SSR markers were lower: 0.2689 in C. japonica (Zhao et al. 2017) and 0.988 in C. nitidissima (Li et al. 2020). Together, these results indicate that C. japonica exhibits high genetic diversity. In general, higher genetic diversity is thought to be associated with a greater ability to adapt to the environment (Reed and Frankham 2003). The high genetic diversity of $C$. japonica (Naidong) may explain why it has successfully survived from the third century.

Populations from the Daqingshan, Changmenyan Island, and Daguan Island generally showed higher genetic diversity, though they are natural island populations. Geographic isolation is a primary cause of differences in genetic diversity within the same species (Bellucci et al. 2013). Island populations exhibit genetic differences as a result of strong genetic drift acting on the population (Forsdick et al. 2017). It is a commonly held view that island species are characterized by geographical isolation, barriers to genetic flow, small population sizes, and possible historical bottleneck effects, which have reduced their population genetic diversity (Francisco-Ortega et al. 2000). Island populations have therefore become models for studying population genetic differentiation (Juan et al. 2000). However, numerous studies have demonstrated that not all island species have low genetic diversity. For example, marginal populations of Cryptomeria japonica on Yaku Island 
Table 5. Analysis of molecular variance (AMOVA) in six Camellia populations.

\begin{tabular}{lrlllc}
\hline Source of variation & \multicolumn{1}{c}{ df } & SS & MS & $\begin{array}{l}\text { Est. } \\
\text { variation }\end{array}$ & $\begin{array}{l}\text { Percentage of } \\
\text { variation (\%) }\end{array}$ \\
\hline Among populations & 5 & 329.489 & 65.898 & 1.744 & 11 \\
Within populations & 174 & 2446.323 & 14.059 & 14.059 & 89 \\
Total & 179 & 2775.811 & & 15.803 & 100 \\
\hline
\end{tabular}

Note: df, degrees of freedom; SS, sum of squares; MS, Mean square.

Table 6. Genetic similarity coefficients of six $C$. japonica populations.

\begin{tabular}{lllllll}
\hline & I & II & III & IV & V & VI \\
\hline Pop I & \multirow{2}{*}{1.0000} & 0.9874 & 0.9721 & 0.8393 & 0.9606 & 0.6738 \\
Pop II & & 1.0000 & 0.9776 & 0.8664 & 0.9671 & 0.6892 \\
Pop III & & & 1.0000 & 0.8646 & 0.9629 & 0.7357 \\
Pop IV & & & & 1.0000 & 0.8338 & 0.6981 \\
Pop V & & & & & 1.0000 & 0.6987 \\
Pop VI & & & & & & 1.0000 \\
\hline
\end{tabular}

Fig. 2. Cluster analysis of six $C$. japonica populations based on genetic distance.

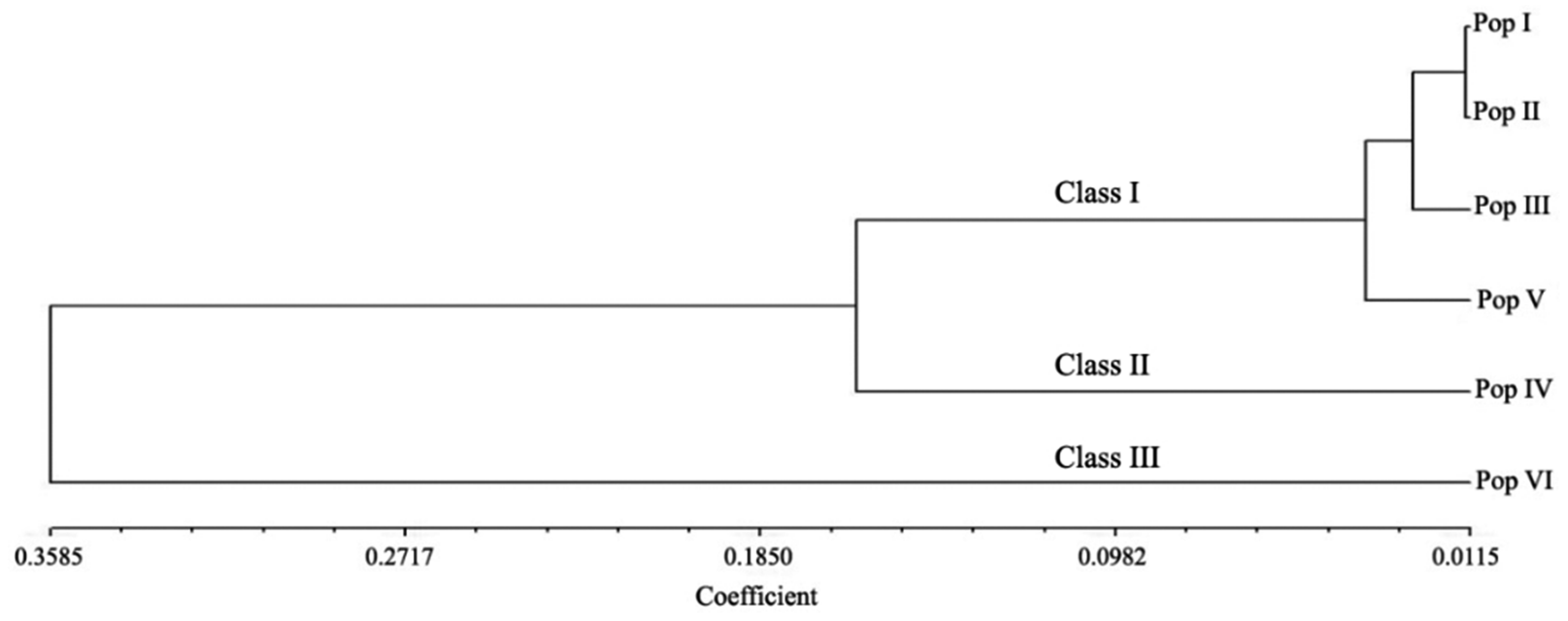

have maintained relatively high genetic variation compared with those of mainland Japan (Tsumura and Ohba 1993). Fineschi et al. (2004) analyzed the genetic diversity of Zelkova schneideriana on the islands of Crete and Sicily and found that the genetic diversity of the island species was high. Li et al. (1996) used allozyme electrophoresis to analyze the genetic diversity of C. japonica populations on the offshore islands of Qingdao and reported a high percentage of polymorphic loci (83.3\%). Here, we found that island $C$. japonica populations (Pop VI, Pop V, and Pop IV) had higher genetic diversity than inland $C$. japonica populations (Pop II and Pop I), confirming that island organisms can maintain high levels of genetic diversity.

The island $C$. japonica population of Daqingshan (Pop VI) had the highest genetic diversity in our study, a finding that may be related to its rich plant species diversity and excellent geographical environment. Daqingshan on Zhujiajian is the main distribution area of wild $C$. japonica. It contains more than 1000 wild C. japonica plants with a rich variation in flower types, petal colors, and leaf shapes, which lead to a variety of breeding types and mating patterns and have caused the amount of genetic variation to increase. Why was higher genetic diversity also found in the two $C$. japonica (Naidong) populations from Daguan Island and Changmenyan Island? A study of Argyroxiphium sandwicense ssp. sandwicense on the island of Hawaii indicated that diversity was closely related to environmental differences; the pressure of natural selection was strong, and the genetic diversity was high (Friar et al. 2010; Zheng et al. 2010). Since the third century, climate 
Fig. 3. STRUCTURE analysis results of $180 \mathrm{C}$. japonica individuals. (a) Population estimation using the mean of estimated log probability of data $(\ln \mathrm{P}(\mathrm{D}))$ with the cluster number $(\mathrm{K})$ varied from 2 to 10 . (b) Population estimation using $\ln \mathrm{P}(\mathrm{D})$-derived delta $\mathrm{K}(\Delta \mathrm{K})$ with the cluster number $(\mathrm{K})$ varied from 2 to 10. $(c)$ Genetic structure estimates of the six populations based on STRUCTURE analysis with cluster number $\mathrm{K}=3$. Each individual is represented by a vertical line, and different colors represent different genetic components. [Colour online.]
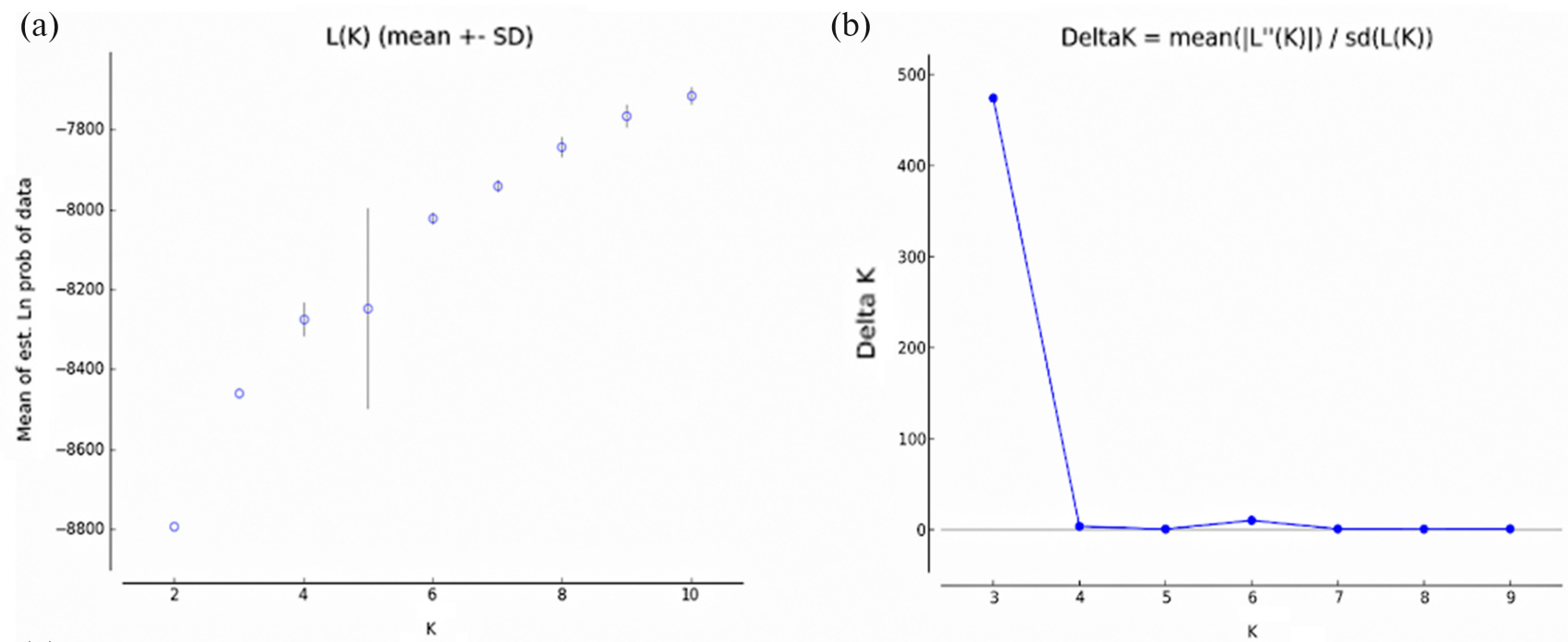

(c)

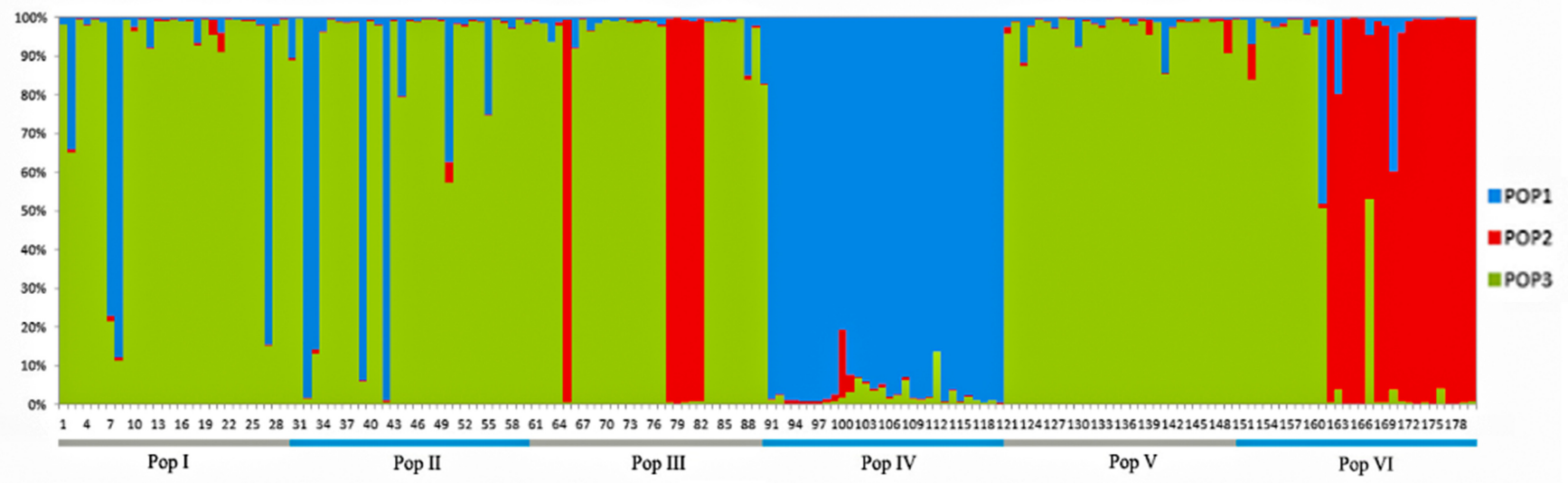

Fig. 4. Principal coordinates analysis (PCoA) of $C$. japonica populations. The colored dots indicated $C$. japonica individuals from different populations. [Colour online.]

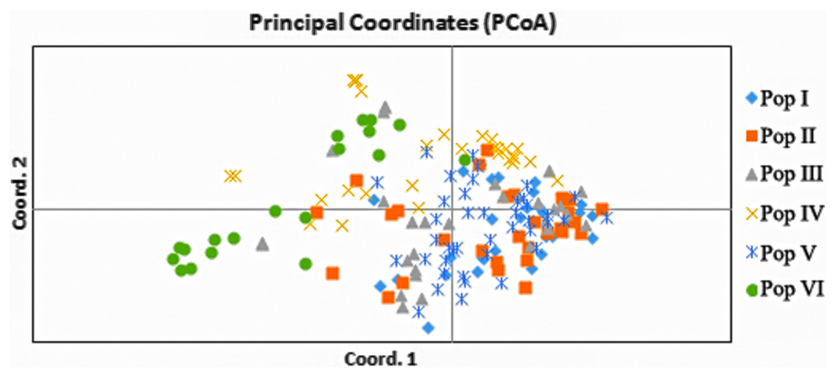

change has produced variable and complex environmental conditions for $C$. japonica (Naidong). Its growth environment on Daguan and Changmenyan islands is relatively harsh, influenced by waves, exposed rocks, shallow soil (usually no more than $50 \mathrm{~cm}$ deep), and a shrinking distribution. Nonetheless, C. japonica (Naidong) has become the dominant tree species on the islands, perhaps because its genetic diversity has increased. Although its habitat is relatively small, human influence has also been relatively low (Zhou et al. 1994; Shi and Song 2005), a fact that may contribute to the high genetic diversity of $C$. japonica (Naidong).

\section{Relationships among $C$. japonica populations}

The clustering results of the six populations based on genetic distance showed that the $C$. japonica (Naidong) populations from May Fourth Square (Pop I), Botanical Garden (Pop II), and Zhongshan Park (Pop III) in Qingdao had the closest genetic relationship. These three populations were grouped with the $C$. japonica (Naidong) population from Changmenyan Island (Pop V) into class I. The clustering results indicated that the three cultivated populations and the natural population of C. japonica (Naidong) on Changmenyan Island were 
closely related. Surveys have shown that the $C$. japonica (Naidong) population from the Botanical Garden in Qingdao was cultivated after the establishment of the garden in 1979. Many wild plants and seeds of $C$. japonica (Naidong) from Changmenyan Island and Daguan Island were transplanted or sown in the garden. Those which survived and multiplied gave rise to a $C$. japonica (Naidong) population in the Botanical Garden. C. japonica (Naidong) in Zhongshan Park and May Fourth Square in Qingdao were transplanted from the Qingdao Botanical Garden in 1988 and 1998, respectively (unpublished). Therefore, these four populations are very closely related. Li et al. (1996) conducted a genetic distance analysis of five $C$. japonica populations from Qingdao and Zhejiang and found that the genetic distance was shortest between the $C$. japonica populations of Changmenyan Island and the Botanical Garden in Qingdao, followed by Daguan Island. Their results agree with those of the present study, confirming that the three cultivated populations of $C$. japonica (Naidong) in Qingdao originated from Changmenyan island.

The relationships among the three island populations of Daqingshan (Pop VI), Daguan Island (Pop IV), and Changmenyan Island (Pop V) were consistent with the close genetic relationships reported for $C$. japonica populations on five geographically clustered islands (Lin et al. $2012 b$ ), indicating that the geographical isolation of the islands may have had an important effect on the genetic differentiation of $C$. japonica populations. At the same time, $C$. japonica (Naidong) exhibits morphological and physiological differences relative to southern $C$. japonica, and these may be the result of the long-term geographical separation of the species (Wang 2006; Hagenblad et al. 2019).

\section{Genetic diversity conservation of $C$. japonica germplasm resources}

C. japonica was the dominant species of the coastal woody plant communities on Changmenyan, Daguan, and Zhoushan Islands. Because of human disturbance, the species is currently found only on hillsides at 30-40 m altitude on Changmenyan and Daguan Islands in Qingdao and at $370 \mathrm{~m}$ altitude on islands in Daqingshan (Wang and Zhang 1992; Zhou et al. 1994; Lin et al. 2013). The AMOVA results showed that the within-population genetic variation of $C$. japonica (89\%) was much higher than the among-population variation (11\%), and similar results were found in a study of C. nitidissima (Li et al. 2020). This result indicates that there is abundant genetic variation within $C$. japonica populations and that genetic variation can therefore be protected at the population level. Hence, we propose that in situ conservation approaches for $C$. japonica populations should be carried out first. We suggest strengthening the protection of the natural $C$. japonica populations on islands. The rapid establishment of nature reserves may be an effective way to save rare and endangered $C$. japonica, avoid the destruction of existing island habitat, increase the environmental protection awareness of island residents, and prohibit seedling harvest and seed collection. These approaches can promote natural regeneration to conserve the genetic diversity of $C$. japonica populations (Wang and Hu 1996). For islands with human settlements (Daguan Island, Daqingshan Island), the government or the villagers' committee should publicize and organize the network of forest rangers. For islands without settlements (Changmenyan Island), the garrison could be responsible. To take full advantage of the protected areas, we should perform scientific research, breeding, and sales of $C$. japonica in an organized manner. For cultivated $C$. japonica populations in parks, we should strengthen the informational programs that educate tourists about $C$. japonica. In addition, a germplasm repository should be established to collect and protect the genetic resources present in $C$. japonica populations through seed collection and seedling cultivation from natural populations.

\section{Conclusions}

In this study, we assessed the genetic diversity and relationships among $180 \mathrm{C}$. japonica individuals from six populations. All analyses indicated that the genetic diversity of $C$. japonica was higher than that of other Camellia species, and island C. japonica populations generally had higher genetic diversity than inland populations. The $180 \mathrm{C}$. japonica individuals in the six populations were divided into three clusters that were consistent with their geographical distributions. We also confirmed that cultivated $C$. japonica (Naidong) from three parks were originally transplanted from Changmenyan Island. There was abundant genetic variation within C. japonica populations, and this variation can therefore be protected at the population level. This study represents the first systematic analysis of the genetic diversity and structure of natural and cultivated C. japonica populations. It provides guidance for protecting genetic resources and making horticultural use of C. japonica.

\section{Acknowledgements}

This research was supported by the Science \& Technology for People's Livelihood Program of Qingdao City (No. 17-3-3-47-nsh), the National Natural Science Foundation of China (No. 31500264), and the High Talents Scientific Research Fund of Qingdao Agricultural University (No. 663-1113343).

\section{References}

Ashburner, M., Ball, C.A., Blake, J.A., Botstein, D., Butler, H., Cherry, J.M., et al. 2000. Gene Ontology: tool for the unification of biology. Nat. Genet. 25: 25. doi:10.1038/75556. PMID:10802651.

Bellucci, E., Bitocchi, E., Rau, D., Nanni, L., Ferradini, N., Giardini, A., et al. 2013. Population structure of barley 
landrace populations and gene-flow with modern varieties. PLoS ONE, 8: e83891. doi:10.1371/journal.pone.0083891. PMID:24386303.

Brian, L. 2009. How to protect the wild service tree (Sorbus torminalis) in Polish forests? Sylwan, 153: 354-360.

Charles, E.F., Jeremie, B.F., Sean, H., Kathleen, S.K., Laura, S., Elijah, A., et al. 2018. Optimizing conservation strategies for a threatened tree species: In situ conservation of white ash (Fraxinus americana L.) genetic diversity through insecticide treatment. Forests, 9: 202. doi:10.3390/f9040202.

Chen, Y.N., Dai, X.G., Hou, J., Guan, H.W., Wang, Y.X., Li, Y., et al. 2016. DNA fingerprinting of oil camellia cultivars with SSR markers. Tree Genet. Genom. 12: 7. doi:10.1007/s11295015-0966-7.

Chung, M.G., and Chung, M.Y. 2000. Levels and partitioning of genetic diversity of Camellia japonica (Theaceae) in Korea and Japan. Silvae Genet. 49: 119-124. doi:10.1086/314290.

Earl, D.A., and vonHoldt, B.M. 2012. Structure Harvester: A website and program for visualizing STRUCTURE output and implementing the Evanno method. Conser. Gene. Resour. 4: 359-361. doi:10.1007/s12686-011-9548-7.

Evanno, G., Regnuat, S., and Gouset, J. 2005. Detecting the number of clusters of individuals using the software structure: a simulation study. Mole. Ecol. 14: 2611-2620. doi:10.1111/j.1365294X.2005.02553.x. PMID:15969739.

Excoffier, L., Laval, G., and Schneider, S. 2005. Arlequin (version 3.0): An integrated software package for population genetics data analysis. Evol. Bioinf. Online, 1:47-50. doi:10.1177/ 117693430500100003.

Fang, W., Cheng, H., Duan, Y., Jiang, X., and Li, X. 2012. Genetic diversity and relationship of clonal tea (Camellia sinensis) cultivars in China as revealed by SSR markers. Plant Syst. Evol. 298: 469-483. doi:10.1007/s00606-011-0559-3.

Felsenstein, J. 1984. Distance methods for inferring phylogenies: a justification. Evolution, 38: 16-24.

Fineschi, S., Cozzolino, S., Migliaccio, M., and Vendramin, G.G. 2004. Genetic variation of relic tree species: the case of Mediterranean Zelkova abelicea (Lam.) Boisser and Z. sicula Di Pasquale, Garfì and Quézel (Ulmaceae). Forest Ecol. Manag. 197: 273-278. doi:10.1016/j.foreco.2004.05.018.

Forsdick, N.J., Cubrinovska, I., Massaro, M., and Hale, M.L. 2017. Genetic diversity and population differentiation within and between island populations of two sympatric Petroica robins, the Chatham Island black robin and tomtit. Conserv. Genet. 18: 275-285. doi:10.1007/s10592-016-0899-1.

Francisco-Ortega, J., Santos-Guerra, A., Kim, S.C., and Crawford, D.J. 2000. Plant genetic diversity in the Canary Islands: a conservation respective. Am. J. Bot. 87: 909-919. doi:10.2307/ 2656988. PMID:10898768.

Friar, E.A., Ladoux, T., Roalson, E.H., and Robichaux, R.H. 2010. Microsatellite analysis of a population crash and bottleneck in the Mauna Kea silversword, Argyroxiphium sandwicense ssp. sandwicense (Asteraceae), and its implications for reintroduction. Mol. Ecol. 9: 2027-2034. doi:10.1046/j.1365-294X.2000. 01111.x.

Gao, J.Y., Parks, C.R., and Du, Y.Q. 2005. Collected species of the genus Camellia-an illustrated outline. Zhejiang Science and Technology Press, Hangzhou, Zhejiang, China.

Joshi, S.P., Gupta, V.S., Aggarwal, R.K., Ranjekar, P.K., and Brar, D.S. 2000. Genetic diversity and phylogenetic relationship as revealed by inter simple sequence repeat (ISSR) polymorphism in the genus Oryza. Theor. Appl. Genet. 100: 1311-1320. doi:10.1007/s001220051440.

Hagenblad, J., Leino, M.W., Hernández, A.G., and Afonso, M.D. 2019. Morphological and genetic characterization of barley (Hordeum vulgare L.) landraces in the canary islands. Genet. Resour. Crop Ev. 66: 465-480. doi:10.1007/s10722-018-0726-2.
Hamrick, J.L. 1989. Plant population genetics, breeding, and genetic resources. Pages 43-63 in Allozyme diversity in plant species. A.H.D. Brown, M.T. Clegg, A.L. Kahler, and B.S. Weir, eds. Sinauer Associates Inc., Sunderland, Massachusetts, USA.

Hughes, A.R., Inouye, B.D., Johnson, M.T., Underwood, N., and Vellend, M. 2008. Ecological consequences of genetic diversity. Ecol. Lett. 11: 609-623. doi:10.1111/j.1461-0248.2008. 01179.x. PMID:18400018.

Juan, C., Emerson, B.C., Oromi, P., and Hewitt, G.M. 2000. Colonization and diversification: Towards a phylogeographic synthesis for the Canary Islands. Trends Ecol. Evol. 15: 104-109. doi:10.1016/S0169-5347(99)01776-0. PMID:10675925.

Kang, M.K., and Huh, M.K. 2014. Spatial distribution pattern of the populations of Camellia japonica in Busan. J. Life Sci. 24: 813-819. doi:10.5352/JLS.2014.24.8.813.

King, B. 2018. Camellia treasures from Japan: Camellia japonica. Camellia J. 72: 16-20.

Li, L., Wang, R.Q., Wang, Z.R., Wang, S.P., and Li, S.W.1996. The study of Naidong Camellia biodiversity in Qingdao (II)-Genetic diversity analysis of populations. Biodiversity Sci. 4: 1-6.

Li, M.M., Cai, Y.L., Qian, Z.Q., and Zhao, G.F. 2009. Genetic diversity and differentiation in Chinese sour cherry Prunus pseudocerasus Lindl., and its implications for conservation. Genet. Resour. Crop Ev. 56: 455-464. doi:10.1007/s10722-0089378-y.

Li, X.L., Wang, J., Fan, Z.Q., Li, J.Y., and Yin, H.F. 2020. Genetic diversity in the endangered Camellia nitidissima assessed using transcriptome based SSR markers. Trees. 34: 543-552. doi:10.1007/s00468-019-01935-1.

Lin, L., Hu, Z.Y., Li, J.Y., Zhu, Z.Y., and Ni, S. 2012a. Analysis on genetic diversity of ten insular populations of Camellia japonica. Acta Hortic. Sin. 39: 1531-1538.

Lin, L., Ni, S., Li, J.Y., Chen, Y., and Ying, Z. 2012b. Study on population genetic diversity of Camellia japonica in 5 islands between China and Japan. Guihaia, 32: 298-303+292.

Lin, L., Hu, Z.Y., Ni, S., Li, J.Y., and Qiu, Y.X. 2013. Genetic diversity of Camellia japonica (Theaceae), a species endangered to East Asia, detected by inter-simple sequence repeat (ISSR). Biochem. Syst. Ecol. 50: 199-206. doi:10.1016/j.bse.2013.03.049.

Nagy, S., Poczai, P., Cernák, I., Gorji, A.M., Hegedús, G., and Taller, J. 2012. PICcalc: An online program to calculate polymorphic information content for molecular genetic studies. Biochem. Gent. 50: 670-672. doi:10.1007/s10528-012-9509-1.

Nei, M. 1972. Genetic distance between populations. Am. Nat. 106: 283-292. doi:10.1086/282771.

Oh, G.S., Kang, S.S., and Chung, M.G. 1996. Temporal genetic structure in Camellia japonica (Theaceae). Genes Genet. Syst. 71: 9-13. doi:10.1266/ggs.71.9.

Pan, L.Q., Li, J.Y., Li, S.C., Fan, Z.Q., Yin, H.F., and He, L.B. 2019. Development of SSR markers based on transcriptome of Camellia japonica and analysis of genetic relationship. J. Beijing For. Univ. 41:111-120. doi:10.13332/j.1000-1522. 20190101.

Peakall, R., and Smouse, P.E. 2012. GenAlEx 6.5: Genetic analysis in Excel. Population genetic software for teaching and research-an update. Bioinformatics, 28: 2537-2539. doi:10.1093/bioinformatics/bts460. PMID:22820204.

Reed, D.H., and Frankham, R. 2003. Correlation between ftness and genetic diversity. Conserv. Biol. 17: 230-237. doi:10.1046/ j.1523-1739.2003.01236.x.

Rohlf, F.J. 1988. NTSYS-pc numerical taxonomy and multivariate analysis system. State University of New York, USA.

Shi, M.Z., and Song, H.X. 2005. Genetic diversity and detective methods of plant. World For. Res. 18: 27-31. doi:10.3969/ j.issn.1001-4241.2005.05.006.

Stinchcombe, J.R., and Hoekstra, H.E. 2008 Combining population genomics and quantitative genetics: finding the genes 
underlying ecologically important traits. Heredity, 100: 158-170. doi:10.1038/sj.hdy.6800937.

Szczeciníska, M., Sramko, G., Wotosz, K., and Sawicki, J. 2016. Genetic diversity and population structure of the rare and endangered plant species Pulsatilla patens (L.) Mill in East Central Europe. PLoS ONE, 11: 1-24. doi:10.1371/journal. pone.0151730.

Tong, Y., and Gao, L. 2020. Development and characterization of EST-SSR markers for Camellia reticulata. Appl. Plant Sci. 8: e11348. doi:10.1002/aps3.11348. PMID:32477844.

Tsumura, Y., and Ohba, K. 1993. Genetic structure of geographical marginal populations of Cryptomeria japonica. Can J. Forest Res. 23: 859-863. doi:10.1139/x93-112.

Wang, H., and Hu, Z. 1996. Plant breed system, genetic structure and conservation of genetic diversity. Chin. Biodiversity. 4: 92-96. doi:10.1007/BF02951625.

Wang, J., Du, Q.M., and Wang, J.X. 2001. The changes of common Camellia resources in Jiaodong peninsula. Sci. Technol. Info. Landsc. 2: 2-9.

Wang, X.B., and Zhang, C.J. 1992. The endangered causes of Camellia japonica and its in-situ conservation in islands around Qingdao city, Shandong province. Guihaia, 3: 272-278.

Wang, K.L. 2006. Studies on the germplasm resources of Naidong(Camellia japonica L.). Beijing Forestry University, Beijing, China.

Wang, S.P., Wang, R.Q., and Li, L. 1995. Studies on the diversity of Naidong Camellia in Qingdao distribution and morphological variation. Chin. Biodiversity, 3: 139-142.

Wolf, A.T., and Harrison, S.P. 2001. Effects of habitat size and patch isolation on reproductive success of the serpentine morning glory. Conserv. Biol. 15: 111-121. doi:10.1111/j.15231739.2001.99341.x.
Xie, W.G., Zhang, X.Q., Ma, X., Cai, H.W., Huang, L.K., Peng, Y., et al. 2010. Diversity comparison and phylogenetic relationships of cocksfoot (Dactylis glomerata L.) germplasm as revealed by SSR markers. Can. J. Plant Sci. 90: 13-21. doi:10.4141/cjps08192.

Yamamoto, S.I. 1992. Gap characteristics and gap regeneration in primary evergreen broad-leaved forests of western Japan. J. Plant Res. 105: 29-45. doi:10.1007/BF02489401.

Yeh, F.C., Yang, R.C., and Boyle, T. 1997. POPGENE, version 1.31, the user- friendly shareware for population genetic analysis. Mol. Biotechnol. 434: 724-731.

Zhang, H.D., and Ren, S.X. 1998. Flora of China (Vol 3,49). Science Press, Beijing, China.

Zhang, L. 2008. Genetic diversity of Camellia japonica in Zhejiang province. Beijing Forestry University, Beijing, China.

Zhang, Y.L., Song, G., and Feng, S.C. 2016. Application of SSR for the analysis of genetic diversity in Camellia. Plant Sci. J. 34: 755-764.

Zhao, Y., Ruan, C.J., Ding, G.J., and Mopper, S. 2017. Genetic relationships in a germplasm collection of Camellia japonica and Camellia oleifera using SSR analysis. Genet. Mol. Res. 16: 1-14. doi:10.4238/gmr16019526.

Zheng, S.H., Wang, K., Zhao, M.L., Mi, J., Sui, X.Q., Feng, Y.F., et al. 2010. Effect of habitat fragmentation on the genetic diversity of Stipa krylovii Reshov. in an agro-pastoral ecotone in northern China. Can. J. Plant Sci. 89: 875-882. doi:10.4141/ CJPS08231.

Zhou, R.L., Yang, Z., Wei, J.G., and Dong, S.G. 1994. Present conditions and restoring measures of Camellia japonica plant community of Changmenyan island. J. Ocean Univ. Qingdao, 24: 71-79. 